\title{
Butterfly Children/Epidermolysis Bullosa
}

\author{
Jaya Pradha Dhandapani
}

\begin{abstract}
Epidermolysis bullosa is a collection of a typical medical conditions that end in easy blistering of the skin and mucous membranes. Its severances can extent from mild to fatal. Children born with it are often called "butterfly children" because their skin seems as brittle as a butterfly wing. Epidermolysis bullosa was first identified in the late $1800 \mathrm{~s}$. Its association is with family of conditions called blistering diseases. There are the top five types of epidermolysis bullosa. Approximately 5,000 people have been affected by this disease in the UK. A positive family history raises the risk, based upon the type of inheritance and the closeness of affected relatives. All kinds of epidermolysis bullosa are genetic through the family so having a history of family or an impaired parent is a risk factor. Generally, signs of epidermolysis bullosa first arise in babies or toddlers. Painful skin and pustules are the major symptoms. Skin biopsy is prime. To make the diagnosis, immunofluorescence is necessary and also electromicroscopy. Treatment option includes minimizing friction, effusing blisters, maintaining a cool temperature, recognizing the signs of infection and maintaining a proper diet. The complications are anemia, oral cavities constipation, dehydration, dry skin, eye problem, infection, malnutrition, and skin cancer.
\end{abstract}

Keywords: Blisters, Butterfly children, Epidermolysis bullosa, Skin.

Pondicherry Journal of Nursing (2021): 10.5005/jp-journals-10084-13106

\section{INTRODUCTION}

Epidermolysis bullosa is a collection of atypical medical conditions that end in easy blistering of the skin and mucous membranes. ${ }^{1}$ Blisters develop with minor trauma or friction and are uncomfortable. Its severances can extent from mild to fatal. ${ }^{1}$ Epidermolysis bullosa simplex (EBS) generally has little or no extra-cutaneous association, while the more severe hemidesmosome, junctional and dystrophic forms of EB may cause remarkable multiorgan system involvement. ${ }^{1}$

\section{Meaning}

Epidermolysis bullosa is an uncommon genetic condition that makes skin so brittle that it can rupture or blister at the minimum touch. ${ }^{2}$ Children born with it are often called "butterfly children" because their skin seems as brittle as a butterfly wing. ${ }^{2}$ Mild forms may get improved with time. In some severe cases, it can be more uncomfortable, provoke other dangerous health issues, and can be fatal. $^{2}$

\section{HISTORY}

Epidermolysis bullosa was first identified in the late 1800 s. Its association of family of conditions called blistering diseases. ${ }^{3}$

- Presentation is commonly at or abruptly after birth but may be prolonged in milder cases. ${ }^{3}$

- Record the age of onset, the site of blisters, and the degree of trauma need to activate. ${ }^{3}$

- List mucous membranes, together with oral, respiratory, nasopharyngeal, genitourinary, and ocular surfaces. ${ }^{3}$

- Some severe epidermolysis bullosa is connected with growth restriction, esophageal strictures, and other abnormalities in the gastrointestinal. ${ }^{4}$

- Urological abnormalities have also been reported. ${ }^{3}$
Department of Obstetrics and Gynecological Nursing, Kasturba Gandhi Nursing College, Sri Balaji Vidyapeeth (Deemed to be University), Puducherry, India

Corresponding Author: Jaya Pradha Dhandapani, Department of Obstetrics and Gynecological Nursing, Kasturba Gandhi Nursing College, Sri Balaji Vidyapeeth (Deemed to be University), Puducherry, India, Phone: +91 7639126403, e-mail: J.pradhaa17@gmail.com

How to cite this article: Dhandapani JP. Butterfly Children/ Epidermolysis Bullosa. Pon J Nurs 2021;14(3):66-68.

Source of support: Nil

Conflict of interest: None

\section{TyPES}

There are the top five types of epidermolysis bullosa. The category may be based on where the blisters tend to develop.

EBS: The most regular type, it first emerges in newborns. It commonly affects the soles of the feet and the palms of the hands. ${ }^{4}$

Junctional epidermolysis bullosa: While it also first emerges in babies, this is a more fatal form that results in vesicles in deep layers of the skin. ${ }^{4}$

Dystrophic epidermolysis bullosa: If they have this type, the skin does not have collagen to hold its grip, or the collagen they have does not function well. This means that the layers of our skin do not seal jointly as they should. Sometimes this type does not appear until early childhood. ${ }^{4}$

Kindler syndrome: This is a varied condition since vesicles occur across various skin layers. It can also cause patchy modification in skin coloring when it shows up to the Sun. ${ }^{4}$

\footnotetext{
(c) The Author(s). 2021 Open Access This article is distributed under the terms of the Creative Commons Attribution 4.0 International License (https://creativecommons. org/licenses/by-nc/4.0/), which permits unrestricted use, distribution, and non-commercial reproduction in any medium, provided you give appropriate credit to the original author(s) and the source, provide a link to the Creative Commons license, and indicate if changes were made. The Creative Commons Public Domain Dedication waiver (http://creativecommons.org/publicdomain/zero/1.0/) applies to the data made available in this article, unless otherwise stated.
} 
Epidermolysis bullosa acquisita: This type of form creates pustules or blisters on our hands and feet as well as in mucous membranes like the mouth. ${ }^{4}$

\section{EPIDEMIOLOGY}

- Population researches are worse by the truth that this is not an invariable disease but a more in number of diseases of alternating severity. ${ }^{3}$ It is likely that many of the patients with mild forms of epidermolysis bullosa remain unidentified. ${ }^{5}$

- It is assumed to affect 1 in 17,000 births. Approximately 5,000 people have been affected by this disease in the UK. ${ }^{2}$

- Both sexes are equally affected. ${ }^{1}$

\section{RISK FACTORS}

A positive family history raises the risk, based upon the type of inheritance and the closeness of affected relatives. ${ }^{4}$

\section{Causes}

All kinds of epidermolysis bullosa are genetic through the family so having a history of family or an impaired parent is a risk factor. ${ }^{5}$ The pattern may be inherited dominantly or recessively. ${ }^{3}$ In the dominant kind, a child can be congenital to the disease if transmitted from a single parent. In the case of recessive type, both parents should have an infected gene for a child to be affected by this disease. EB is dreadful when it is inherited recessively. ${ }^{5}$

\section{SyMPTOMS}

Generally, signs of epidermolysis bullosa first arise in babies or toddlers. Painful skin and pustules are the major symptoms. ${ }^{6}$ They can develop anywhere on the skin. ${ }^{2}$ Sometimes they also form on the eyes, or in parts of the throat, stomach, or bladder. If these blisters become contaminated or scar the skin, they cause serious issues. $^{6}$

- Skin that blisters abruptly.

- Vesicles inside the mouth.

- Vesicles on the hands and soles of the feet.

- Scarred skin lies frequently with small white spots called milia.

- Hardened skin and nails.

- Tooth decay.

- Malformed or absences of finger/toenails.

- Internal vesicles in the throat, stomach, and intestines.

- Blistering in scalp and hair loss.

- Profuse sweating.

- Hardening of the skin on the feet or hands.

- White bump in this plug showing through a thin layer of skin.

- Dysphagia.

The symptoms differ from the different kinds of disease.

\section{Diagnosis}

Skin biopsy is important and routine microscopy may aid to eliminate other causes. To make the diagnosis, immunofluorescence is necessary, and also electron microscopy. ${ }^{7}$

- Full blood count (FBC) and iron studies are also important in dystrophic kinds.

- Swabs should be taken to examine infection. ${ }^{7}$
- With centile charts, record height and weight regularly.

- Albumin may be less. ${ }^{7}$

- If accessible, DNA mutation analysis may be executed. ${ }^{8}$

- If a family has had gene tracing, it is feasible to make a diagnosis in the antenatal period with the help of chorionic villus sampling or amniocentesis. ${ }^{9}$

- Gastrointestinal imaging may be needed, e.g., if a web of esophageal is figured. ${ }^{9}$

\section{Treatment}

Home care tips: To limits vesicles, they need to take complete care of our skin. ${ }^{10}$

Minimize friction: Apply lotion to keep our skin moist and decrease friction. To cover wounds, utilize only dressings that are not adhesive and then not too tight to wrap again with gauze rolled. Fit in loose clothes without tags or tight sleeves. ${ }^{8}$

Effuse blisters: If left uncared, these can lead to fluid accumulation and become infected. The doctor will teach them to drain the fluid in a best way. ${ }^{13}$

Maintain cool temperature: Maintain the bathwater no hotter than the room temperature. Stay in air conditioning as much as possible as they can evade heat and humidity. ${ }^{11}$

Recognize the signs of infection: A skin may change red or hot when touched if it is infected. ${ }^{12}$ They could also observe any pus or a yellow discharge at the site, a red streak below the skin, or have increased temperature or rigor/chills. If any of these signs are noticed, inform a physician immediately. If it occurs, antibiotic is needed. ${ }^{12}$

Maintain diet:The majority of people with epidermolysis bullosa as minimum levels of iron, selenium, or vitamin D. The physician may recommend the nutritionists about taking plenty of foods rich in vitamins and minerals. ${ }^{13}$

\section{Life Span of a Person with Epidermolysis BuLLOSA}

Death and impairment are highly differing according to the kind of disease. Death in infancy can happen from infection. ${ }^{14}$ In the more severe recessive types, death from skin cancer is generally between the ages of 15 and 35 but, in the acute, dominant forms, life span is unchanged. ${ }^{15}$

\section{Complications}

Observing for and treating complications: The vesicles and wounds can cause other health issues, where the physician is needed for any complications arising. ${ }^{14}$ Treatment modalities for complications may include the following:

- Anemia: Proper wound care and cutting off (and treating) an infection can decrease the loss of blood, it may cause anemia. When anemia emerges, iron supplements, intravenous iron infusion, or transfusion of blood can resolve it. ${ }^{14}$

- Cavities and other issues in the mouth: Disease in gums and cavities is common in people who have epidermolysis bullosa. Patients may require a dentist, who has specialized in treating epidermolysis bullosa, for every 3 months.

- Constipation:This disease can make bowel movement pain more severe. With the help of a dietitian, they can reduce constipation and other issues like diarrhea by altering the patient's diet. 
- Dehydration: Open wounds can cause dehydration. This can be resolving by encouraging plenty of fluids to drink. If persist, the child will require an IV fluid to replace fluid loss. If it occurs, antibiotic is needed.

- Dry skin: Using a moisturizer cream every day can decrease skin dryness, which can prevent blistering, pain, and itching. If a nurse is taking care of a wound, apply moisturizer. ${ }^{5}$

- Excess sweating: Generally in patients with this kind of EB seems as an EBS, treating profuse sweating. Treating it can decrease pustules and itching.

- Eye problems: Eyesores, blistering in eyelids, and other eye problems can happen. When treated immediately and it could be better. $^{14}$

- Infection: Proper wound care and good nutrition can also prevent infection. Treatment often includes dressing in bandages regularly and taking an antibiotic. Chronic infection can dissolve for a long time. ${ }^{7}$

- Malnutrition: Malnutrition also happens when vesicles form in the mouth or esophagus because taking food becomes too painful. A dietitian can help to suggest foods that a child can take; in some situations, the child needs a feeding tube.

- Skin cancer: Skin cancer can occur in areas with prolonging standing wounds and scars. The goal of treatment is to dissolve all of the cancer. ${ }^{14}$

\section{Conclusion}

EB is an unusual genetically determined, blistering disorder transmitting both sexes, such as males and females, with the most noticeable engagement of hands and feet..$^{13}$ In the deprivation of specific therapy, treatment mainly involves associated with maladaptive of provoking factors, preventive measures, and treatment modalities of complication. ${ }^{15}$

\section{References}

1. Fine JD, Raj E, Bauer E, et al. The classification of inherited Epidermolysis Bullosa (EB): report of the third international consensus meeting on diagnosis and classification of EB. J Am Acad Dermatol 2008,58:931-950. DOI: 10.1016/j.jaad.2008.02.004.

2. Weston WL, Lane AT, Morelli JG, editors. Color textbook of pediatric dermatology. 4th ed. Maryland Heights: Mosby/Elsevier, 2007, pp. 348-354.
3. Fine JD, Mellerio JE. Extra cutaneous manifestations and complications of inherited epidermolysis bullosa: part I. Epithelial associated tissues'. Am Acad Dermatol 2009;61(3):367-384. DOI: 10.1016/j.jaad.2009.03.052.

4. Pfendne EG, Bruckner A, Conget $P$, et al. Basic science of epidermolysis bullosa and diagnostic and molecular characterization: proceedings of the IInd international symposium on epidermolysis bullosa. Santiago, Chile, 2005. Int J Dermatol 2007;46(8):781-794. DOI: 10.1111/j.1365-4632.2007.03307.x.

5. Aziz Khan RG, Denyer JE, Mellerio JE, et al. Surgical management of epidermolysis bullosa: proceedings of the IInd international symposium on epidermolysis bullosa, Santiago, Chile, 2005. Int J Dermatol 2007:46(8):801-808. DOI: 10.1111/j.1365-4632.2007.03313.x.

6. Mellerio JE, Weiner M, Denyer JE, et al. Medical management of epidermolysis bullosa: proceedings of the IInd international symposium on epidermolysis bullosa, Santiago, Chile, 2005. Int J Dermatol 2007;46(8):795-800. DOI: 10.1111/j.13654632.2007.03316.x.

7. Lucky AW, Pfendner E, Pillay E, et al. Psychosocial aspects of epidermolysis bullosa: proceedings of the IInd international symposium on epidermolysis bullosa, Santiago, Chile, 2005. Int J Dermatol 2007;46(8):809-814. DOI: 10.1111/j.1365-4632.2007.03311.x.

8. Coulombe PA, Kerns ML, Fuchs E. Epidermolysis bullosa simplex: a paradigm for disorders of tissue fragility. J Clin Invest 2009;119(7):1784-1793. DOI: 10.1172/JCl38177.

9. Pfendner E, Rouan F, Uitto J. Progress in epidermolysis bullosa: the phenotypic spectrum of plectin mutations. Exp Dermatol 2005;14(4):241-249. DOI: 10.1111/j.0906-6705.2005.00324.x.

10. Rugg EL, Leigh IM. The keratins and their disorders. Am J Med Genet C Semin Med Genet 2004;131C(1):4-11. DOI: 10.1002/ajmg.c.30029.

11. Castori M, Floriddia G, De Luca N, et al. Herlitz junctional epidermolysis bullosa: laminin-5 mutational profile and carrier frequency in the Italian population. Br J Dermatol 2008;158(1):38-44. DOI: $10.1111 /$ j.1365-2133.2007.08208.x.

12. Has C, Liu L, Bolling MC, et al. Clinical practice guidelines for laboratory diagnosis of epidermolysis bullosa. $\mathrm{Br} J$ Dermatol 2020;182(3):574-592. DOI: 10.1111/bjd.18128.

13. Pulkkinen $\mathrm{L}$, Uitto J. Mutation analysis and molecular genetics of epidermolysis bullosa. Matrix Biol 1999;18(1):29-42. DOI: 10.1016/ s0945-053x(98)00005-5.

14. Varki R, Sadowski S, Pfendner E, et al. Epidermolysis bullosa. I. Molecular genetics of the junctional and hemidesmosomal variants. J Med Genet 2006;43(8):641-652. DOI: 10.1136/jmg.2005.039685.

15. Charlesworth A, Chiaverini C, Chevrant-Breton J, et al. Epidermolysis bullosa simplex with PLEC mutations: new phenotypes and new mutations. Br J Dermatol 2013;168(4):808-814. DOI: 10.1111/bjd.12202. 